\title{
Analysis of flow fields associated with freely swimming calanoid copepods
}

\author{
M. H. Bundy*, G.-A. Paffenhöfer \\ Skidaway Institute of Oceanography, 10 Ocean Science Circle, Savannah, Georgia 31411, USA
}

\begin{abstract}
High-resolution video observations of freely swimming adult female copepods were utilized to characterize the flow fields produced by Centropages velificatus, an omnivore with strong tendencies toward carnivory, and Paracalanus aculeatus, a herbivore. Horizontal and vertical components of the translational velocity of the copepod were subtracted from the corresponding components of flow field velocity, allowing fluid velocities to be calculated from an external frame of reference and without the need for mechanical restraints on the copepod. Large differences in the geometry of flow fields were found between species. The flow field geometry of $P$. aculeatus is similar between individuals, and lower in velocity than the flow field of $C$. velificatus. The flow field geometry of $C$. velificatus is variable between individuals and seems to be dependent on copepod body orientation and swimming trajectory. Evidence is presented that a third factor, fluid distortion around the moving copepod, also affects the flow field geometry. The ecological implications regarding behavioral plasticity and the influence of flow field velocity and geometry on the feeding success of copepods in the field are discussed.
\end{abstract}

KEY WORDS: Feeding current - Calanoid copepod · Feeding behavior Zooplankton

\section{INTRODUCTION}

This investigation examines the spatial dimensions and velocity structure of flow fields generated by freely swimming calanoid copepods, with the goal of relating swimming behavior to flow field geometry, and to copepod foraging success. The fluid which is displaced as the copepod propels itself with its appendages forms a feeding current which entrains prey and may transmit cues about the presence and/or location of prey (Andrews 1983, Legier-Visser et al. 1986). Early studies of copepod feeding currents differentiated between the flows which entrained food particles (twin vortices around the mouthparts) and those which propelled the copepod (larger vortices around the cephalothorax) (Storch \& Pfisterer 1925, Cannon 1928, Gauld 1966). Later studies showed that the flows are laminar, sheared in two dimensions (Strickler 1982), and create a force which results in the translation of the copepod

\footnotetext{
- Present address: Great Lakes Environmental Research Laboratory, 2205 Commonwealth Blvd, Ann Arbor, Michigan 48105, USA.E-mail: bundy@glerl.noaa.gov
}

through the water (Koehl \& Strickler 1981, Paffenhöfer, et al. 1982, Strickler 1984, Svetlichnyy 1987, Fields \& Yen 1993). The translational force opposes non-rotational movement along the trajectory of the copepod. For freely swimming copepods, forces which oppose the translational force generated by the feeding current have been identified as gravity (or negative buoyancy) and drag (Strickler 1982, Emlet \& Strathmann 1985).

In the present study, the flows which propel the copepod are not considered to be physically separate from the flows which entrain particles, although they are considered to have separate implications for predator-prey interactions. The 2 components together help control the volume which can be sampled for potential prey by the copepod. This volume is constrained by the perceptive range of the copepod and is equivalent to the reactive field described by Strickler (1985) for herbivorous copepods. Encounter rates with prey are a function of the volume contacted by the cross-section of the reactive field as the foraging copepod moves (Rosenthal \& Hempel 1970) and the patterns of movement of the copepod (Cushing 1968, Gerritsen \& Strickler 1977). 
The velocity structure of the fluid moved by the appendages and displaced by the body of the copepod as it moves, the flow field sensu Fields \& Yen (1993), also controls encounter rates with food items by creating a hydrodynamic disturbance which can trigger escape responses in motile prey such as copepod nauplii and rotifers (Williamson 1987, Williamson \& Vanderploeg 1988, Yen \& Fields 1992). Flow field shear is implicated as the stimulus which alerts motile prey to the presence of a feeding copepod (Gilbert \& Kirk 1988, Yen et al. 1991, Yen \& Fields 1992). Omnivorous and carnivorous copepods also may be alerted to the presence of potential food items by hydrodynamic disturbances created by prey which move to escape the feeding current (Kerfoot 1978, Haury \& Kenyon 1980. Yen \& Fields 1992)

The geometry of the flow field created by a stationary organism differs from that of the organism as it moves as a result of producing the flows (Strickler 1982, Emlet 1990). Therefore, as Strickler writes (in Alcaraz et al. 1980), tethering cannot be used to accurately study the flow fields of copepod species which nurmally move against the flow field current. Both Centropages velificatus and Paracalanus aculeatus use their flow fields for propulsion as well as for food capture. For this reason, examination of unrestrained copepods is necessary to accurately measure flow fields. To accomplish this, we mathematically remove the translational velocity of the copepod from the velocities of particles in the appendage-generated feeding current. In effect, we have created an analytical tether rather than a physical tether and the dynamics of the flow field can therefore be investigated both from an outside frame of reference and from the perspective of the copepod.

\section{FILMING METHODS}

Adult Centropages velificatus (cephalothorax length $1.2 \mathrm{~mm}$ ) were collected from vertical plankton tows made 24 to $64 \mathrm{~km}$ off the coast of Georgia, USA. Approximately 20 to 30 females and 2 to 4 males were placed in an $8 \mathrm{l}$ holding vessel with $7 \mathrm{l}$ of glass-fiber filtered seawater from the collection site to which $1.5 \mathrm{~mm}^{3} \mathrm{l}^{-1}\left(5 \times 10^{4}\right.$ cells $\left.^{-1}\right)$ of the dinoflagellate Gymnodinium nelsoni were added. Either $0.3 \mathrm{~mm}^{3} \mathrm{l}^{-1}$ of the centric diatom Thalassiosira weissflogii $\left(2 \times 10^{5}\right.$ cells $\left.1^{-1}\right)$ or $T$ eccentrica $\left(1 \times 10^{4}\right.$ cells $\left.1^{-1}\right)$ were added as inert optical markers of fluid flows. Copepods were acclimated to these algae for 50 to $60 \mathrm{~h}$ under a $12: 12 \mathrm{~h}$ light:dark regime before filming. After acclimation, the copepods were placed in complete darkness for 1 to $2 \mathrm{~h}$ prior to videotaping in a $6 \mathrm{l}$ cubic filming vessel, in the dark.
To examine the flow field without the influence of the movement of the copepod, several female Centropages velificatus were also videotaped in a $31 \mathrm{film}$ ing vessel while tethered to short cat hairs (Alcaraz et al. 1980). Phytoplankton concentrations were $1.4 \mathrm{~mm}^{3}$ $1^{-1}$ Gymnodinium nelsoni and $0.3 \mathrm{~mm}^{3} \mathrm{l}^{-1}$ Thalassiosira eccentrica. The hairs were glued to a thin gold wire which could be easily bent, allowing the copepods to be positioned in front of the video camera.

Paracalanus aculeatus females (cephalothorax length $1.0 \mathrm{~mm}$ ) were reared in the laboratory on Gymnodinium nelsoni and the cryptomonad Rhodomonas sp. in 2 I jars mounted on a rotating wheel which revolved at $0.25 \mathrm{rpm}$. The copepods were acclimated to $0.5 \mathrm{~mm}^{3}$ $1^{-1}\left(4 \times 10^{4}\right.$ cells $\left.1^{-1}\right)$ Thalassiosira eccentrica for 24 to 48 h prior to videotaping. Copepods were placed in complete darkness for 1 to $2 \mathrm{~h}$ in a $3 \mathrm{l}$ cubic filming vessel containing $1.0 \mathrm{~mm}^{3} \mathrm{l}^{-1} T$. eccentrica, then videotaped. The concentrations of $T$, eccentrica and $G$. nelsoni used in the filming experiments provided satiating levels of food for $P$. aculeatus and $C$. velificatus, respectively (Paffenhöfer et al. 1995, Bundy unpubl. obs.).

Three copepods from each species were filmed individualiy for 30 to $60 \mathrm{~min}$ using a video camera with an infrared light source mounted on a 3-dimensional motor drive system. The optical setup was similar to that described by Strickler (1985). A digital record of camera position was collected at a sampling rate of $3 \mathrm{~s}^{-1}$ The area of the video camera field of view was $16 \times 13 \mathrm{~mm}$. Spatial resolution was $15 \mu \mathrm{m}$ in the plane of view of the video camera and approximately $200 \mu \mathrm{m}$ in the camera plane of focus.

\section{DATA ANALYSES}

Video tapes were analyzed using a motion analysis system (Peak Performance Technologies, Inc.) which allowed the positions of copepods and surrounding particles in each video field to be digitized and recorded. Particle velocities of $1 \mathrm{~mm} \mathrm{~s}^{-1}$ resulted in a particle displacement from field to field which approached video screen resolution. For this reason, even though video images were collected at a rate of 60 fields $s^{-1}$, only every other video field was analyzed

Only lateral views of the copepod were analyzed because of the low resolution in the camera plane of focus. Although dorsal and ventral views of the copepod also provide information about vertical components of flow field velocity, there is no way of determining the orientation of the copepod body, or whether the copepod is moving into or out of the field of view. Information about copepod body orientation is necessary to relate feeding current geometry to the orienta- 
tion of the appendages and to swimming posture. To determine orientation of the copepod, the coordinates of the left and right first antennae (A1), the eye, the base of the urosome, and the tip of the urosome of the copepod were digitized along with 4 phytoplankton cells (Fig. 1). Of the 4 phytoplankton cells, 1 was located remotely from the copepod and was used as a reference point. Cells used as reference particles were more than $3.5 \mathrm{~mm}$ away from the copepod at all times, with most being more than $5 \mathrm{~mm}$ away. Their velocities were always less than $0.3 \mathrm{~mm} \mathrm{~s}^{-1}$ when observed with the camera not moving. The remaining 3 cells were close to the copepod and their trajectories were used to track feeding current flows. Each set of points comprised a time-series representing the positions of the 4 cells and the copepod. No data were collected if copepods moved within 5 body lengths of the filming vessel wall, bottom or water surface

Each trajectory in each time-series was subjected to a low-pass digital filter to remove high frequencies associated with digitizing error (Weiss et al. 1986). A Butterworth filter with cut-off frequency of $6 \mathrm{~Hz}$ was utilized. At least 1950 data points, representing the trajectories of at least 40 cells, were digitized for each Centropages velificatus female. Since the average swimming velocity of Paracalanus aculeatus females was less than half that of $C$. velificatus, more than 3000 data points were digitized for each $P$. aculeatus female (see Table 1). Particle velocities were calculated within a $6 \times 6 \mathrm{~mm}$ area centered around the copepod eye. The position of the copepod eye was designated as the location of the copepod. Particle trajectories in the flow field were calculated from the displacement of each point relative to the position of the copepod eye. Particle trajectories were rotated relative to the orientation of the longitudinal axis of the copepod body during each time-series. Velocities of particles were calculated from displacements. The displacement of the eye relative to the reference point particle was used to calculate the swimming velocity of the copepod at each point in the time-series.

To eliminate the translational velocity of the copepod from velocities of the feeding current flow, cell velocities were decomposed into horizontal $(u)$ and vertical (v) components, and the respective components of the copepod velocity were subtracted. This method of analysis provides an external frame of reference for the copepod and its flow field. The horizontal and vertical planes of reference are the horizontal and vertical planes of the filming vessel. Velocity data were spatially averaged and plotted as contour plots using the gridding method of Smith \& Wessel (1990) with grid points every $0.1 \mathrm{~mm}$. Using MatLab ${ }^{\star}$, a data processing package developed by Mathworks, Inc., velocity isolines were drawn, and vectors providing qualitative

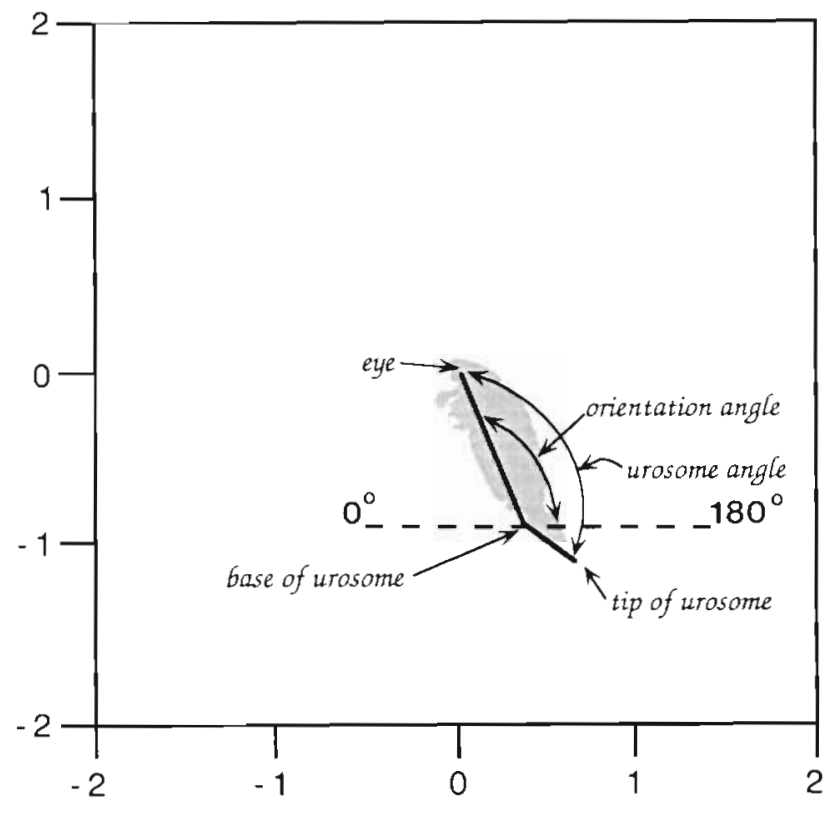

Fig. 1. Silhouette of copepod body and the area around a freely swimming copepod from which flow field data were analyzed. Angles describing posture and orientation of the copepod are depicted as urosome angle and orientation angle, respectively

information about flow direction were placed at each grid point.

Because of particle movement into and out of the field of view, our calculations underestimate the magnitudes of fluid velocity for both tethered and freely swimming copepods. These parameters must therefore be compared in the context of their horizontal and vertical components. The trajectories of flow in lateral views appear to pass through the body of the copepod because fluid moves around the body of the copepod. Shear is not calculated in this study because of the lack of information about fluid velocity in the third dimension of the feeding current (flow into and out of the plane of view). However, areas of high shear in the flow field can be identified by the close spacing of velocity isolines.

The behavior of each copepod is characterized by the velocity and trajectory of movement and by the posture of the copepod. The trajectory of the copepod is revealed by examining the relative contribution of the horizontal and vertical components of swimming velocity. The posture of the copepod is described by the angle of the copepod body axis, which is the line between the eye and the base of the urosome (orientation angle), and by the angle formed by the body axis and the urosome (urosome angle) (Fig. 1). The orientation angle is calculated relative to the $x$-axis, which is parallel to the bottom of the filming vessel and perpendicular to the force of gravity. 


\section{RESULTS}

Fig. 1 represents a lateral view of a freely swimming copepod and the points used for spatial analyses. Fig. 2 and Figs. $3 \& 5$ show a $6 \times 6 \mathrm{~mm}$ and a $4 \times 4 \mathrm{~mm}$ area, respectively, of the flow field centered at the copepod eye. A silhouette of the copepod at its average orientation and urosome angle is overlaid on the diagrams. A long arrow indicating the swimming trajectory of each individual is superimposed on figures representing flow field geometry (Figs. $3 b$ \& 5b). The orientation of the copepod as it swims is determined from the orientation angle, while the position of the urosome is determined from the urosome angle. Table 1 shows the behavioral data associated with each freely swimming copepod.

\section{Tethered Centropages velificatus}

Particle velocities and the geometry of the flow field around a tethered Centropages velificatus are shown in Fig. 2. The flow field influences particles as far away as $3.5 \mathrm{~mm}$ (approximately 3 body lengths). Fluid velocity increases sharply anterior-ventrally (Fig. 2a, b). There are 2 high velocity areas in this region, with maxima of 15 and $18 \mathrm{~mm} \mathrm{~s}^{-1}$. The presence of multiple velocity maxima indicates that the flows are moving into, and consequently out of, the plane of view. It is also possible that the flow field is pulsed, as has been observed very close to the copepod in the flow field of a tethered Eucalanus pileatus (Koehl \& Strickler 1981). The flow field of this copepod is similar in geometry and velocity structure to the flow fields of 2 other tethered $C$. velificatus females that we observed.

Velocity isolines of both the horizontal $(u)$ and vertical $(v)$ components of flow field velocity within a $6 x$ $6 \mathrm{~mm}$ area are centered anterior-ventrally to the tethered copepod (Fig. 2c). Fluid is displaced in a ventral to dorsal direction (Fig. 2b). Maximum horizontal velocities are 7 and $8 \mathrm{~mm} \mathrm{~s}^{-1}$ and maximum vertical velocities are 14 and $16 \mathrm{~mm} \mathrm{~s}^{-1}$. The location of these max- ima corresponds to the location of the resultant velocity maxima seen in Fig $2 \mathrm{a}$.

\section{Freely swimming Centropages velificatus}

We quantified the velocity and geometry of the flow fields generated by freely swimming Centropages velificatus females (Fig. 3). The flow fields of copepods 1 and 3 (Cv1 and Cv3, respectively) are similar in geometry, with areas of high velocity located ventrally and anterior-ventrally (Fig. 3a). These high velocity areas extend for $1.5 \mathrm{~mm}$ away from the copepod. An area of reduced velocity is located adjacent to the mouthparts because particles are drawn in anterior-ventrally and moved away posterior-ventrally. Flow field diagrams (Fig. 3b) show that fluid moves vertically upward in front of the A1 of Cv3 where it appears to join with flows which separate around the A1. Flow begins separating due to the boundary layer approximately $0.5 \mathrm{~mm}$ anterior to the copepod, and fluid velocities are elevated dorsally (Fig. 3a, b). Maximum velocity is $6 \mathrm{~mm} \mathrm{~s}^{-1}$ and $7 \mathrm{~mm} \mathrm{~s}^{-1}$ for $\mathrm{Cv} 1$ and $\mathrm{Cv} 3$, respectively. For these copepods, the vertical component of feeding current velocity is much greater than the horizontal component (Fig. 3c).

The body orientation angles of $\mathrm{Cv} 1$ and $\mathrm{Cv} 3$ are less than $90^{\circ}$ (Table 1), indicating that on average, both copepods tilted backward while swimming. The body orientation of Cv1 and Cv3 changes gradually during each time-series (Fig. 4). Visual observations showed that these copepods followed curved paths as they swam upward for 3 to $6 \mathrm{~s}$ then, at the apex of each path, sank for 2 to $3 \mathrm{~s}$ at approximately $2 \mathrm{~mm} \mathrm{~s}^{-1}$ to a vertical position close to the starting location. Average urosome angles are $114^{\circ}$ and $108^{\circ}$, respectively, for Cv1 and Cv3. The horizontal component of swimming velocity is negligible for Cv1, while for Cv3, the horizontal component is approximately half the magnitude of the vertical component (Table 1).

The second Centropages velificatus female (Cv2) differs from $\mathrm{Cv} \hat{\imath}$ and $\mathrm{Cv} 3$ in both its swimming behav-

Table 1. Centropages velificatus (Cv1-Cv3) and Paracalanus aculeatus (Pa1-Pa3). Copepod swimming velocity, trajectory, and orientation (mean \pm SD). Numbers of data points and cell paths represent those within a $6 \times 6$ mm area centered at the copepod eye

\begin{tabular}{|c|c|c|c|c|c|c|c|}
\hline Copepod & $\begin{array}{c}\text { No, of } \\
\text { data points }\end{array}$ & $\begin{array}{l}\text { No. of } \\
\text { cell paths }\end{array}$ & $\begin{array}{l}\text { Copepod velocity } \\
\left(\mathrm{mm} \mathrm{s}^{-1}\right)\end{array}$ & $\begin{array}{l}\text { Horizontal velocity } \\
\qquad\left(\mathrm{mm} \mathrm{s}^{-1}\right)\end{array}$ & $\begin{array}{l}\text { Vertical velocity } \\
\qquad\left(\mathrm{mm} \mathrm{s}^{-1}\right)\end{array}$ & $\begin{array}{c}\text { Orientation angle } \\
\text { (degrees) }\end{array}$ & $\begin{array}{l}\text { Urosome angle } \\
\text { (degrees) }\end{array}$ \\
\hline Cv1 & 2015 & 52 & $1.8 \pm 0.63$ & $0.0 \pm 0.71$ & $1.6 \pm 0.72$ & $76 \pm 10.0$ & $114 \pm 7.8$ \\
\hline Cv2 & 2721 & 66 & $2.8 \pm 0.58$ & $2.7 \pm 0.57$ & $0.6 \pm 0.57$ & $132 \pm 6.4$ & $130 \pm 8.5$ \\
\hline $\mathrm{Cv} 3$ & 1959 & 42 & $2.9 \pm 0.49$ & $1.0 \pm 0.64$ & $2.7 \pm 0.46$ & $70 \pm 9.1$ & $108 \pm 15.4$ \\
\hline $\mathrm{Pa} 1$ & 4103 & 54 & $1.0 \pm 0.31$ & $1.0 \pm 032$ & $0.0 \pm 0.27$ & $122 \pm 4.1$ & $102 \pm 1.9$ \\
\hline $\mathrm{Pa} 2$ & 4017 & 48 & $1.0 \pm 0.31$ & $1.0 \pm 0.32$ & $0.0 \pm 0.28$ & $109 \pm 3.0$ & $103 \pm 1.4$ \\
\hline $\mathrm{Pa} 3$ & 3009 & 40 & $0.6 \pm 0.28$ & $0.6 \pm 0.32$ & $0.0 \pm 0.26$ & $96 \pm 4.4$ & $102 \pm 1.6$ \\
\hline
\end{tabular}



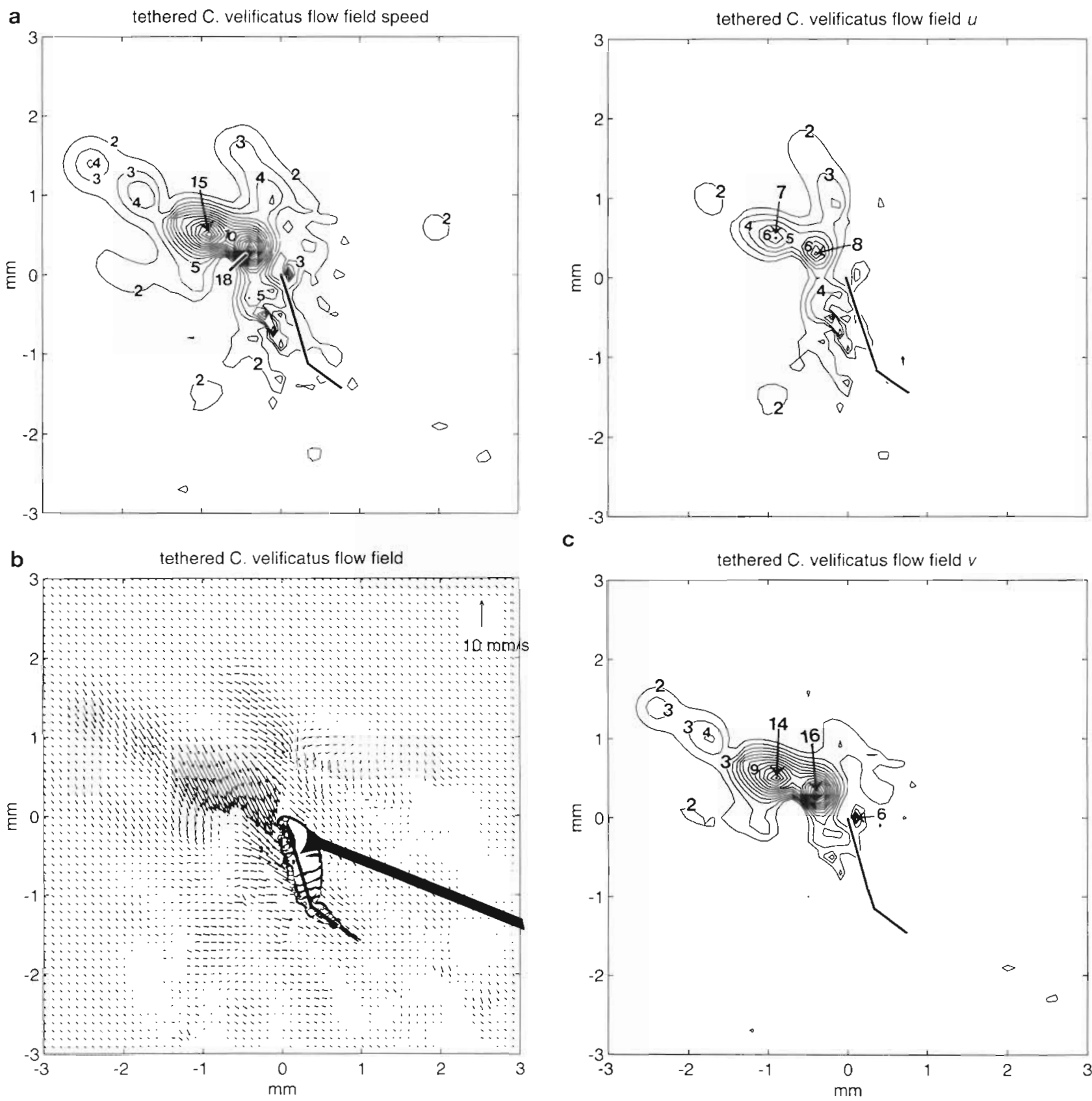

C

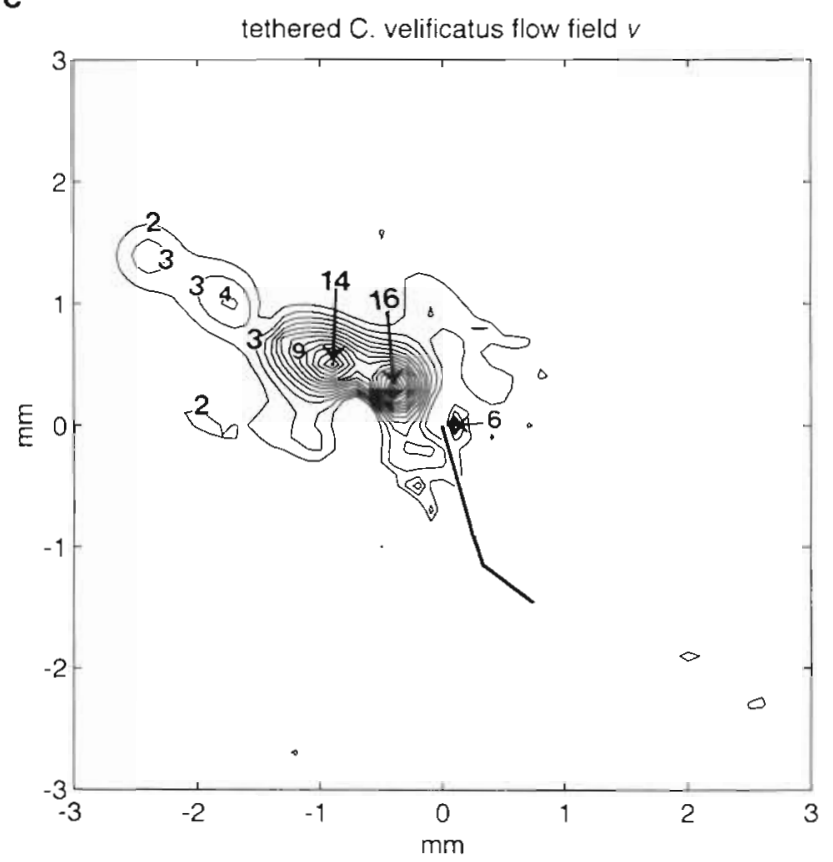

Fig. 2. Feeding current of a tethered female Centropages velificatus. (a) Flow field velocity. Contours represent fluid speeds and are plotted at $1 \mathrm{~mm} \mathrm{~s}^{-1}$ intervals. (b) Flow field geometry. Vectors indicate direction and magnitude of flow. (c) Horizontal (u) and vertical $(v)$ components of feeding current velocity. Isolines are plotted at $1 \mathrm{~mm} \mathrm{~s}^{-1}$ intervals

ior and its feeding current flow field. The feeding current flow field is characterized by lower fluid velocity than Cv1 and Cv3 (Fig. 3a). The areas of elevated velocity extend anteriorally and dorsally for $2 \mathrm{~mm}$ but the magnitudes of velocity are low. There is also an area of elevated velocity located anterior-ventrally, approximately $0.5 \mathrm{~mm}$ from the copepod. Fluid is diverted anterior-dorsally around the horizontally moving copepod and flows move over the A1 (Fig. 3b).
Both vertical and horizontal components of velocity contribute to feeding current velocity (Fig, 3c).

The body orientation of Cv2 remains relatively constant during each time-series, compared to that of Cv1 and $\mathrm{Cv} 3$ (Fig. 4), and visual observations revealed that the swimming paths were linear. In contrast to Cv1 and Cv3, this copepod alternated long ( 3 to 12 s) bouts of linear swimming activity with short $(0.5$ to $1 \mathrm{~s})$ sinking bouts. At the end of each sinking bout, the copepod 
a
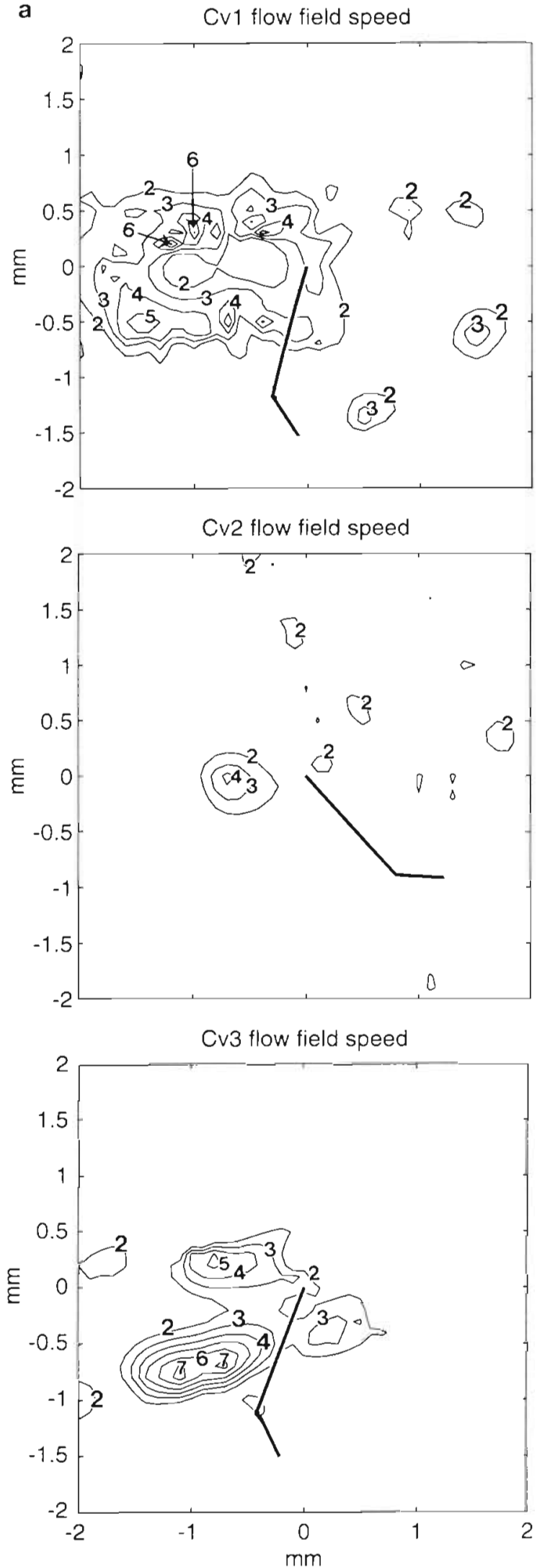

b Cv1 feeding current flow field
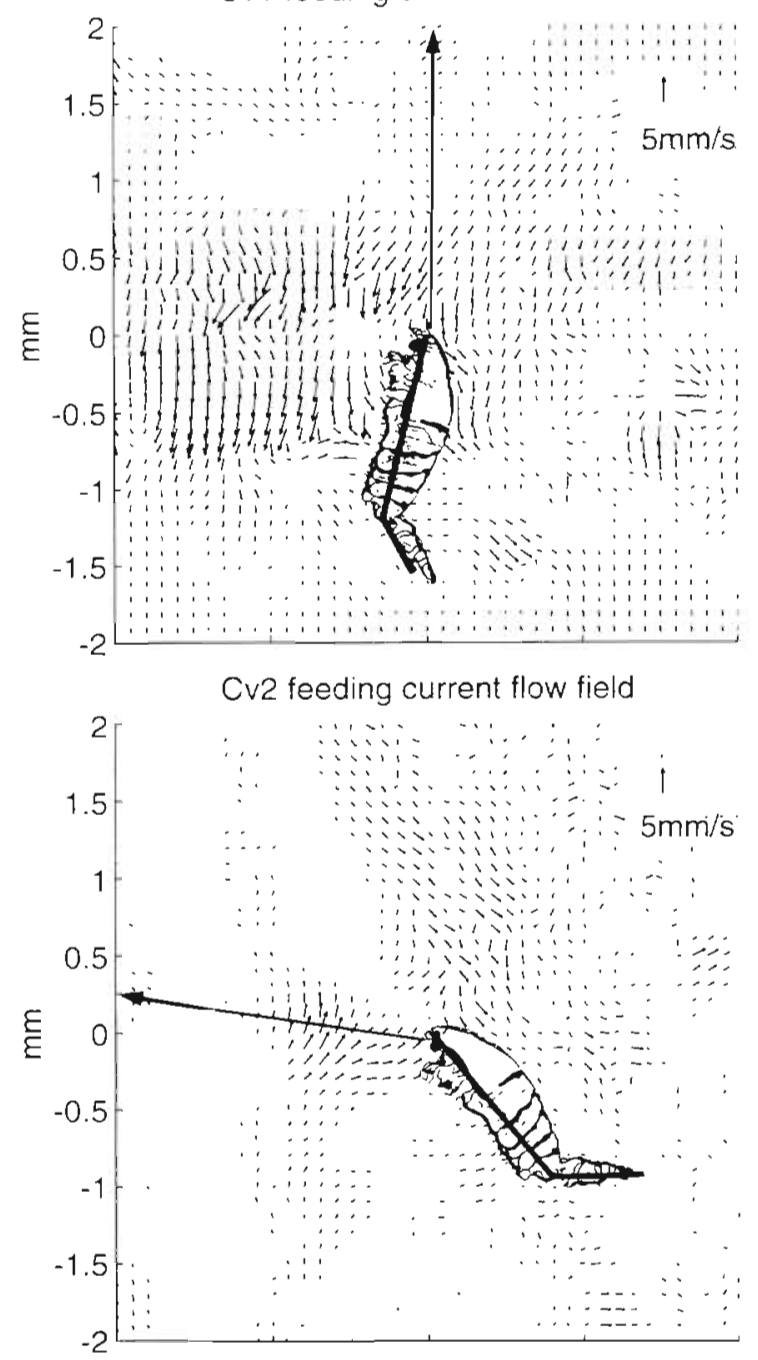

Cv3 feeding current flow field

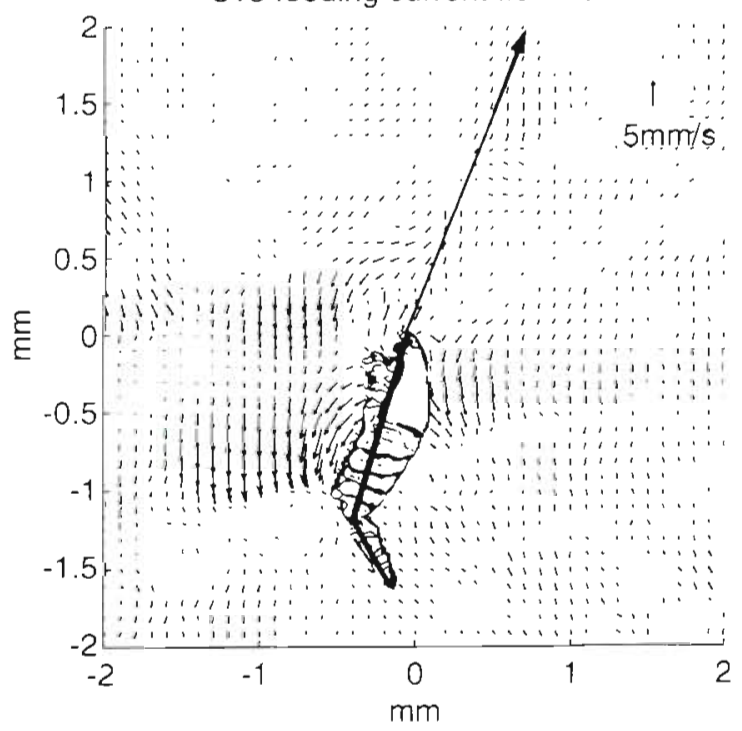


C
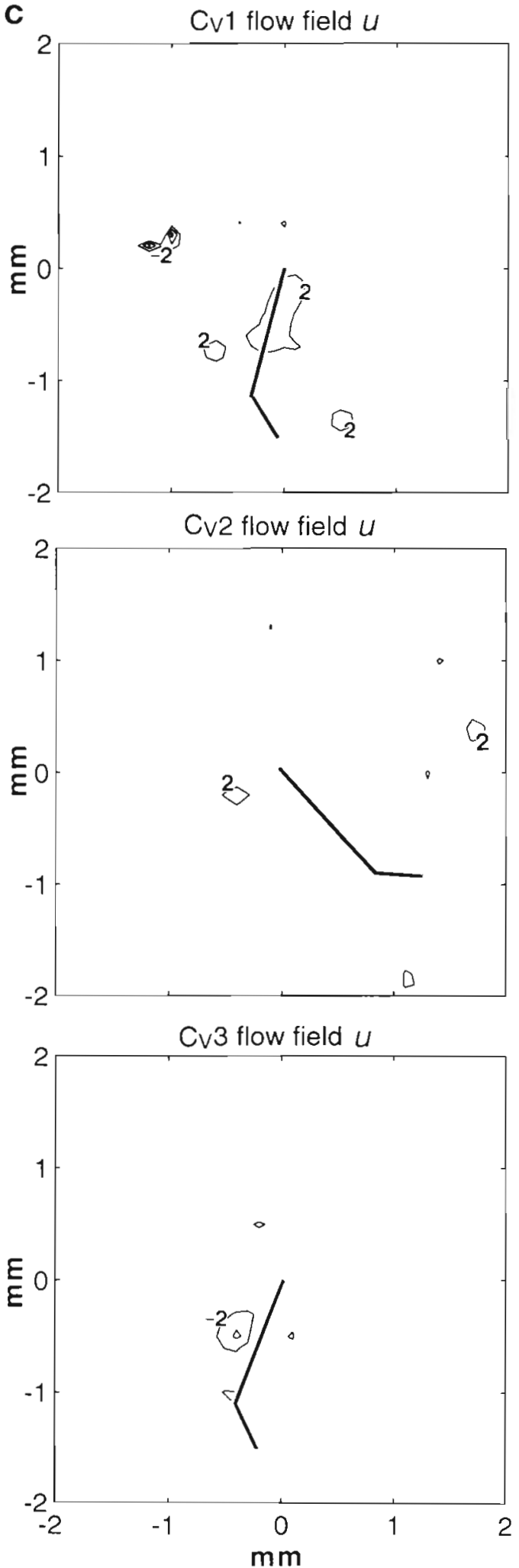

Cv1 flow field $v$

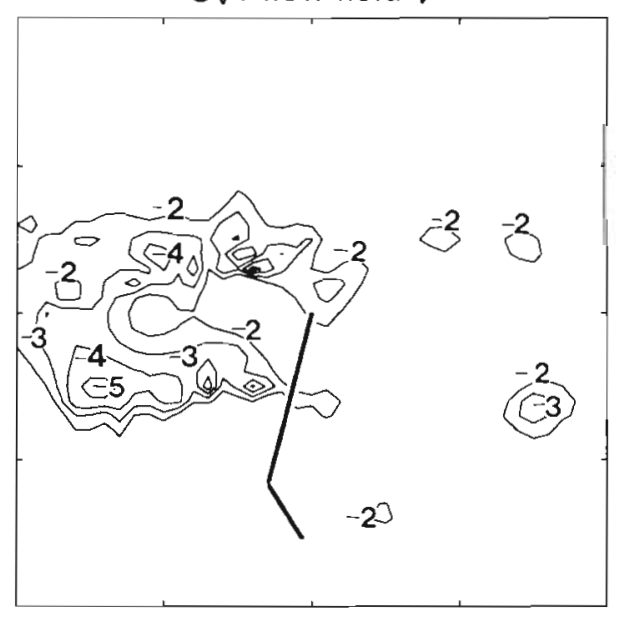

Cv2 flow field $V$

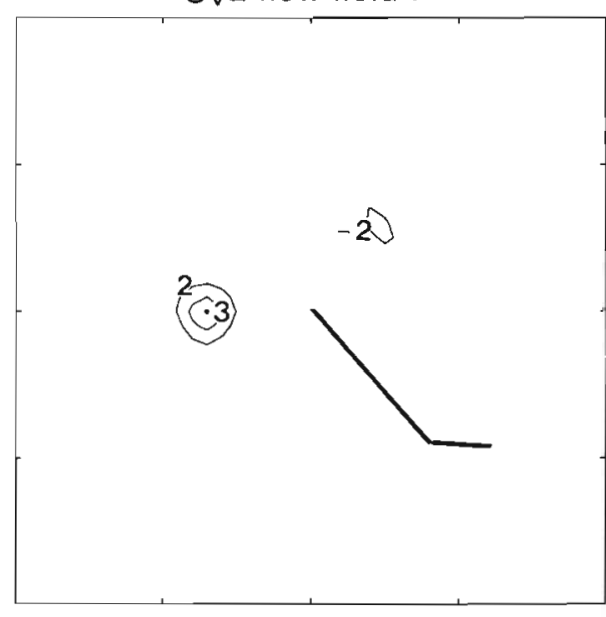

CV3 flow field $v$

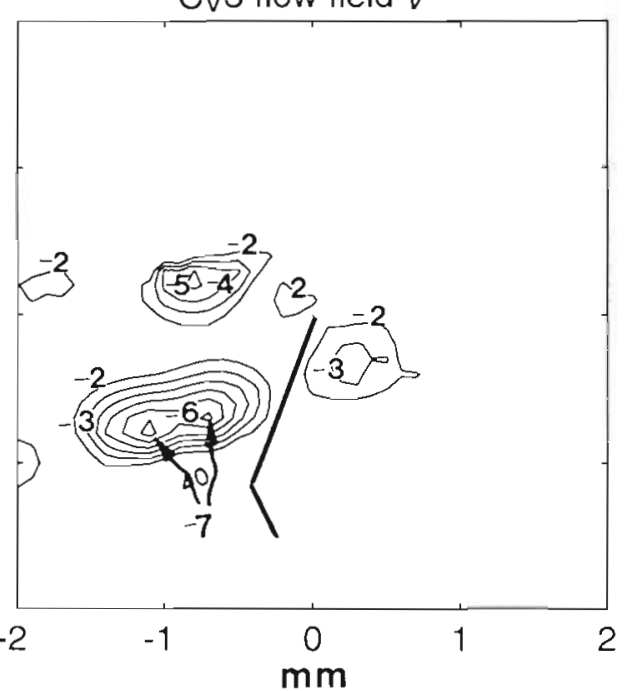

Fig. 3 (facing page and above). The feeding current of Centropages velificatus females. (a) Flow field velocity. Contours represent fluid speeds and are plotted at $1 \mathrm{~mm} \mathrm{~s}^{-1}$ intervals. (b) Flow field geometry. Vectors indicate direction and magnitude of flow. Single large arrow represents copepod swimming trajectory. (c) Horizontal ( $u$ ) and vertical ( $v$ ) components of feeding current velocity. Isolines are plotted at $1 \mathrm{~mm} \mathrm{~s}^{-1}$ intervals 

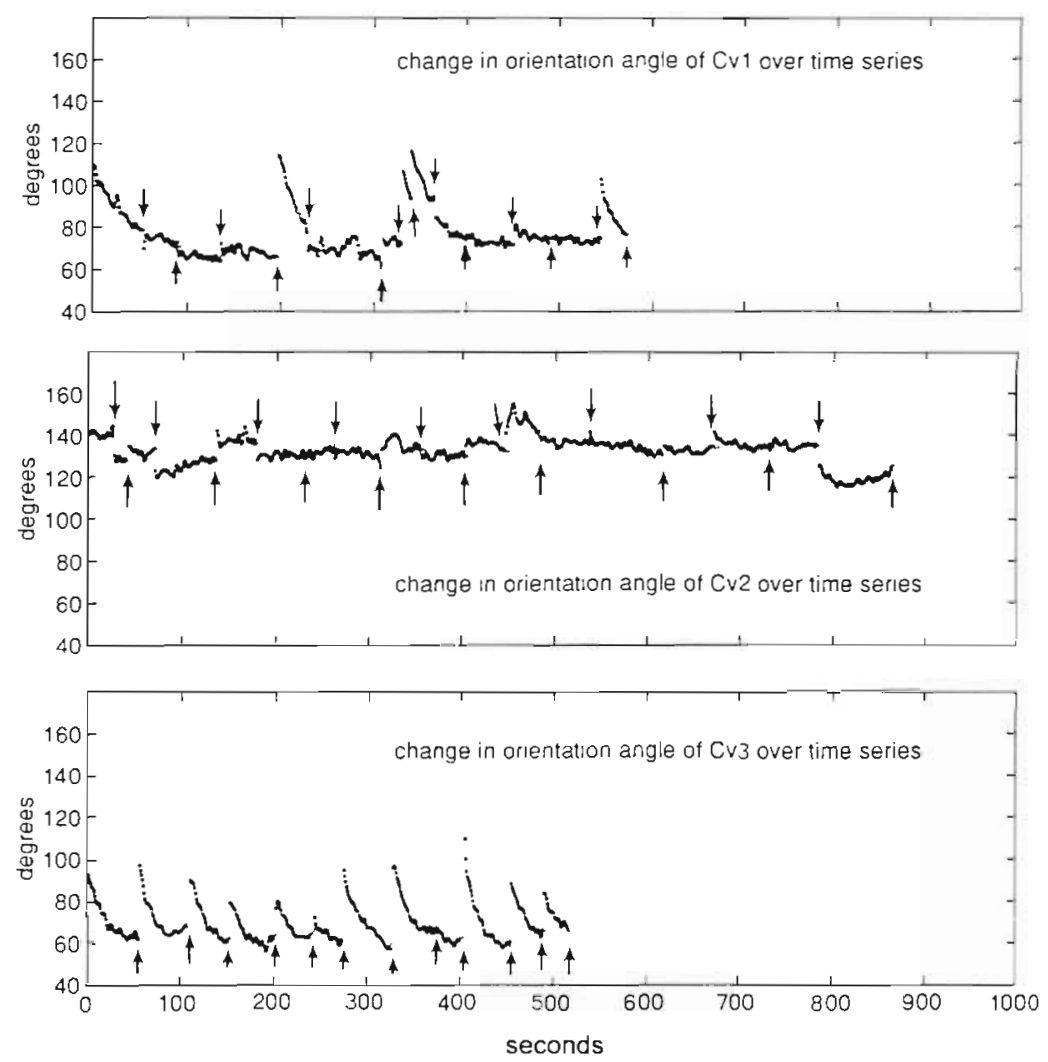

Fig. 4. Centropages velificatus. Changes in body orientation over each timeseries. Arrows represent the end of each time-series. $y$-axis is angle of the copepod body axis (orientation angle) (see Fig. 1). Each dot is $0.033 \mathrm{~s}$ apart

executed rapid turns by flicking either of its A1. Although swimming velocity is not significantly higher than that of the other 2 copepods, the horizontal component of swimming velocity is 3 times that of the vertical component (Table 1). Mean orientation angle is $132^{\circ}$, indicating that this copepod tilted forward while swimming. The average urosome angle is more obtuse than that of Cv1 and Cv2 (Table 1), resulting in a posture which presumably would present less drag. An extensive boundary layer with reduced velocities is located anterior to $\mathrm{Cv} 2$, and velocities are high dorsal to the copepod (Fig. 3b).

\section{Freely swimming Paracalanus aculeatus}

The feeding current flow fields of the 3 Paracalanus aculeatus females ( $\mathrm{Pa} 1, \mathrm{~Pa} 2$, and $\mathrm{Pa} 3$ ) are similar to each other in geometry, and generally exhibit lower velocities than the Centropages velificatus females (Fig. 5). The zone of influence of the feeding current extends approximately $1.5 \mathrm{~mm}$ dorsally from the copepod eye and 0.5 to $1.0 \mathrm{~mm}$ ventrally from the mouth- parts. There are 2 distinct areas of high velocity located anterior-dorsally and ventrally (Fig 5a). Flow field diagrams and component diagrams (Fig. 5b, c) indicate that horizontal velocity dominates at the mouthpart region, while vertical components of velocity are pronounced anterior to the copepods. Highest velocities are adjacent to the mouthparts for all 3 copepods (Fig. 5a).

The body orientations of the copepods are relatively constant during each timeseries (Fig 6). The average orientation angles are greater than $90^{\circ}$ (Table 1), indicating that the copepods tilted forward while swimming. Pa 3 had the most vertical posture (orientation angle $=96^{\circ}$ ). The horizontal component of swimming velocity is an order of magnitude greater than the vertical component (Table 1) for all. 3 copepods. Visual observations revealed that swimming paths were linear and Paracalanus aculeatus females rarely exhibited periodic sinking and swimming activity like that of the Centropages velificatus females. P. aculeatus females changed direction in the horizontal plane by flicking an antenna and turning rapidly. They also occasionally ceased appendage movement and sank at approximately $2 \mathrm{~mm} \mathrm{~s}^{-1}$. Flow field diagrams (Fig. 5b) reveal that fluid is accelerated across the A1. There are low velocity areas approximately $0.5 \mathrm{~mm}$ in front of the $\mathrm{A} 1$ of $\mathrm{Pa} 1$ and $\mathrm{Pa} 2$, while the flow field of $\mathrm{Pa} 3$ shows little distortion in the A1 region (Fig. 5b). Flows for the latter copepod extend farther anterior-ventrally, and the vertical component of flow dominates above the copepod while the horizontal component dominates in front of the copepod, around the mouthparts (Fig. 5a, b).

\section{DISCUSSION}

\section{Methodological rationale}

By using freely swimming copepods in this study, the velocity structure of feeding current flow fields could be examined without artifacts imposed by tethers. For freely swimming copepods, flow field velocity and geometry are controlled by the balance of forces which resist movement through the fluid (drag and negative buoyancy) and the forces exerted on the fluid by the appendages (Strickler 1982). As this study shows, the body orientation of the copepod changes as it swims 
therefore causing the effects of drag to vary. This observation is supported by observations that flow field shear is reduced and swimming velocity increases as Eucalanus crassus alters its body orientation to the flow (Strickler 1982). If a copepod is prevented from moving forward by an artificial tether, the force of the appendages on the fluid will result only in displacement of fluid (the feeding current), not in movement of the copepod.

The effect of the tether is seen in the enhanced magnitude and the difference in location of high fluid velocities around the tethered copepod (Fig. 2), when compared to the freely swimming copepods (Figs. 3 \& 5). The shape of the boundary layer around a moving copepod is altered by tethering because the location of high velocity flow is shifted and velocities are enhanced. The higher feeding current velocity of the tethered Centropages velificatus, relative to the freely swimming copepods, results because a component of the force that the appendages of the freely swimming copepod exert on the fluid is utilized for translation of the copepod through the fluid, rather than for moving fluid toward the copepod. Increasing fluid velocity reduces the boundary layer. The distortion of streamlines (the boundary layer) around the dorsal surfaces of the freely swimming C. velificatus (Fig. $3 b$ ) is not present in the flow field diagram of the tethered copepod (Fig. 2b).

It is important to examine freely swimming individuals to fully understand the flow fields generated by copepods which vary their swimming velocity and body orientation while moving. It may, however, be appropriate to tether copepod species which remain more or less stationary while creating a feeding current and which show little change in body orientation in response to changes in patterns of mouthpart movement (e.g. Eucalanus hyalinus females). For these species, it can be assumed that the coefficient of drag and/or negative buoyancy is large enough to counteract the feeding current force and artificial tethers should have a limited effect on the feeding current flow fields (Strickler 1984). There is also no evidence that tethering an organism alters patterns of mouthpart movements. If organisms do not alter their trajectories while swimming, flow field artifacts associated with tethering can be avoided by placing the organisms in a flow which has the same velocity as the swimming velocity of the organism (Emlet 1990, Gallager 1993).

\section{Mechanisms which control flow field geometry}

The frequency and patterns of mouthpart movement may control feeding current geometry. When calanoid copepods feed on small cells, the paired mouthparts move in a synchronous opening and closing pattern. Centropages typicus moves the second antennae and maxilliped at $50 \mathrm{~Hz}$ in figure-eight patterns which are almost $180^{\circ}$ out of phase (Cowles \& Strickler 1983). The first maxillae flap at the same frequency. The synchronized motion of the mouthparts generates the feeding current and propels the copepod. The appendages can also move independently to redirect water parcels containing food items (Alcaraz et al. 1980, Koehl \& Strickler 1981, Cowles \& Strickler 1983, Vanderploeg \& Paffenhöfer 1985, Price \& Paffenhöfer 1986, Paffenhöfer \& Lewis 1990). Paracalanus parvus creates a feeding current mainly with its second antennae and large maxillipeds (Price et al. 1983). C. velificatus has rather small maxillipeds which should not contribute much to the creation of the feeding current. This is reflected in the geometry of the flow field of C. velificatus (Fig. $3 b$ ) where the direction of flow for Cv1 and Cv3 is largely parallel to the longitudinal body axis, as compared to the flow field of $P$. aculeatus (Fig. $5 b$ ) where the direction of flow is largely directed ventrally and perpendicular to the longitudinal body axis. These species-specific differences in the mechanisms used to generate a feeding current may explain the differences in flow field structure between $C$. velificatus and $P$. aculeatus.

Differences in feeding current velocity between conspecifics in this study may result from differences in the frequency of appendage movements (Centropages velificatus, approximately $50 \mathrm{~Hz}$; Paracalanus aculeatus, approximately $85 \mathrm{~Hz}$; Paffenhöfer unpubl.) or from differences in patterns of appendage movement, as well as from the observed changes in swimming velocity and body orientation (changes in drag). Changes in food concentrations, and exposure to animal versus phytoplankton prey, can also evoke changes in copepod swimming behavior (Bainbridge 1949, Cowles \& Strickler 1983, Jonsson \& Tiselius 1990). In the present study, swimming patterns should be considered characteristic of 'high food' behavior for both species because copepods were acclimated to and videotaped in satiating concentrations of phytoplankton.

The distortion of streamlines or boundary layer around the body and A1 of the moving copepod will influence the hydrodynamic disturbance generated by the moving copepod. For a rapidly moving predator, the boundary layer is thicker along the 'leading edge' of the copepod. The thickness of the boundary layer is dependent on the geometry of the copepod body and A1, and on the velocity and trajectory of copepod movement. Hydrodynamic disturbances are reduced in the boundary layer, and the copepod should be able to approach prey in this region more closely than in other areas of the feeding current, as noted from fewer escape behaviors of copepod nauplii when entrained in this region (Tiselius \& Jonsson 1990) 
a
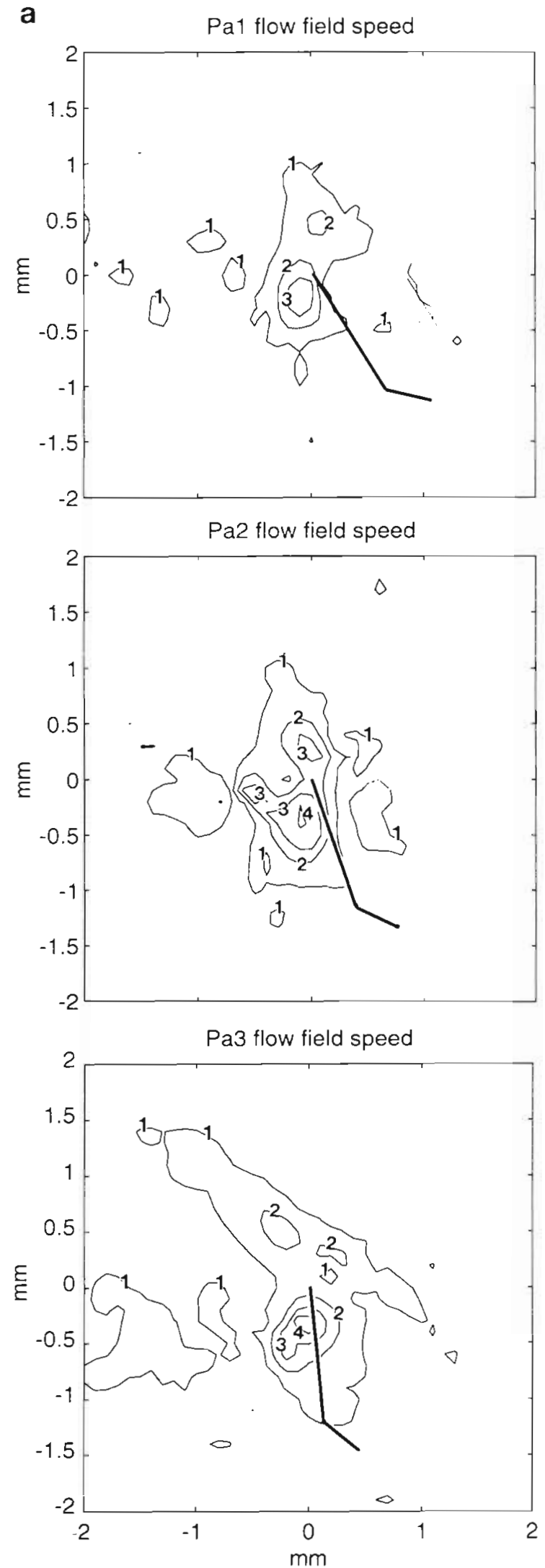

b

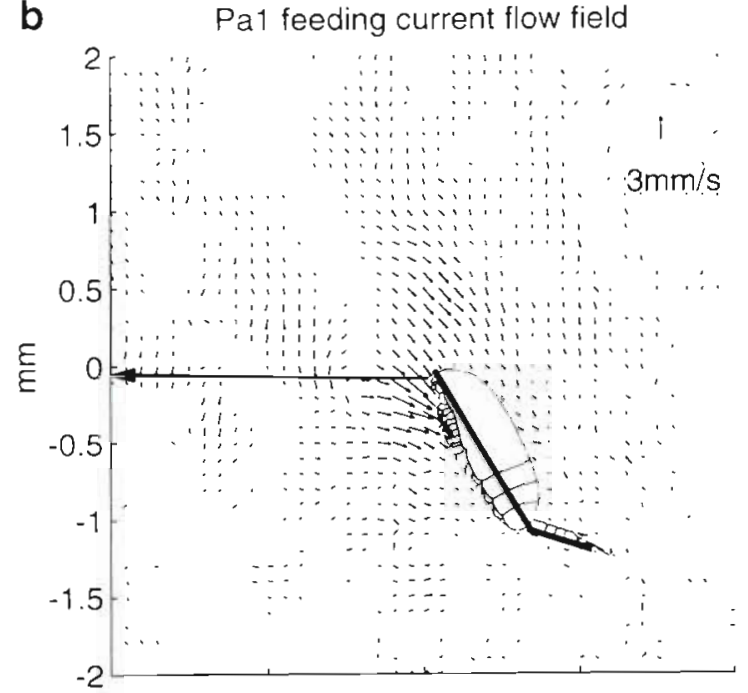

$\mathrm{Pa} 2$ feeding current flow field

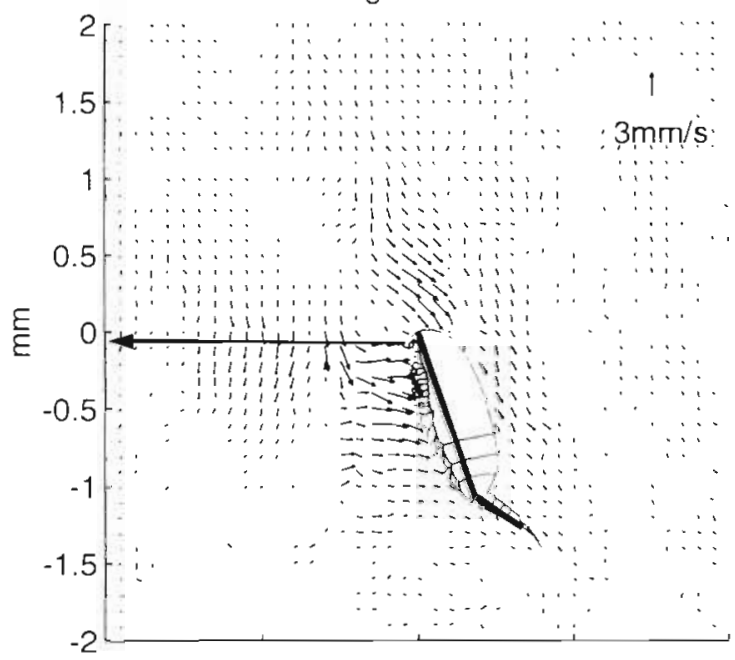

Pa3 feeding current flow field

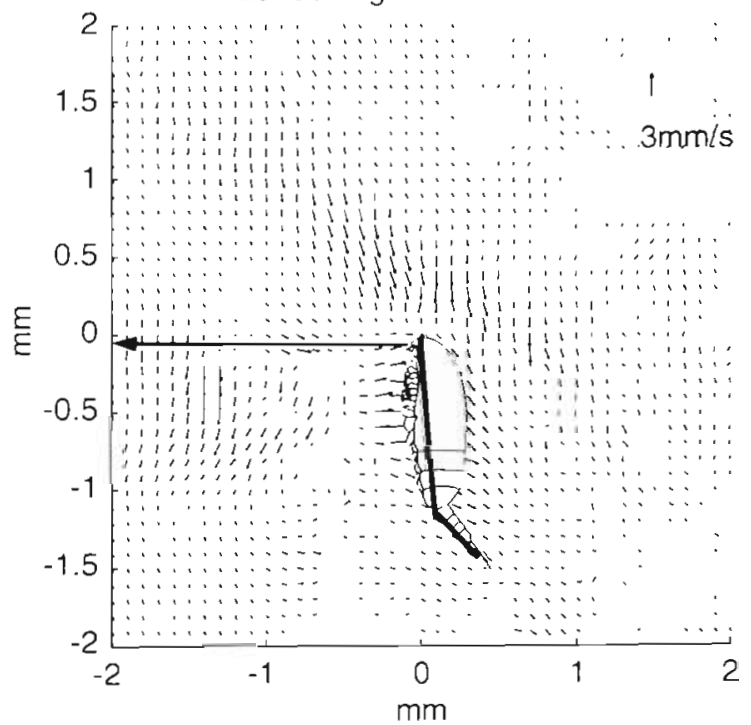


C
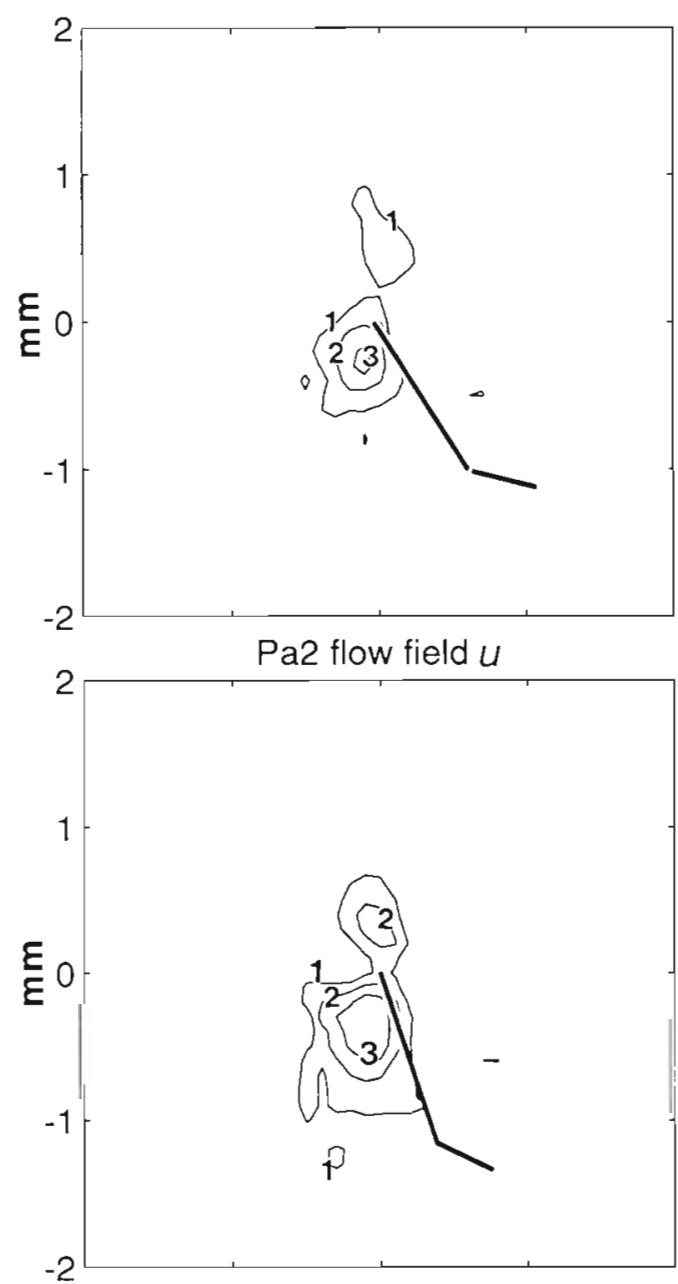

Pa3 flow field $u$

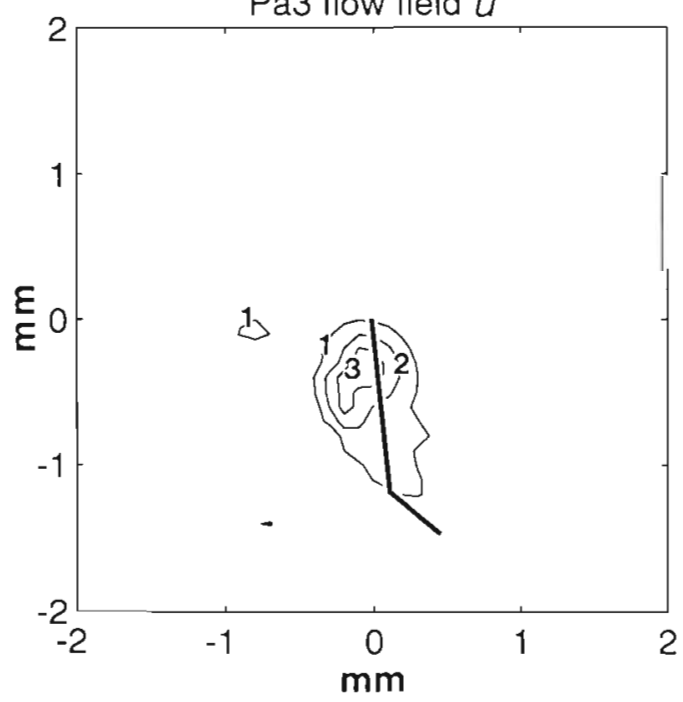

Pa1 flow field $V$

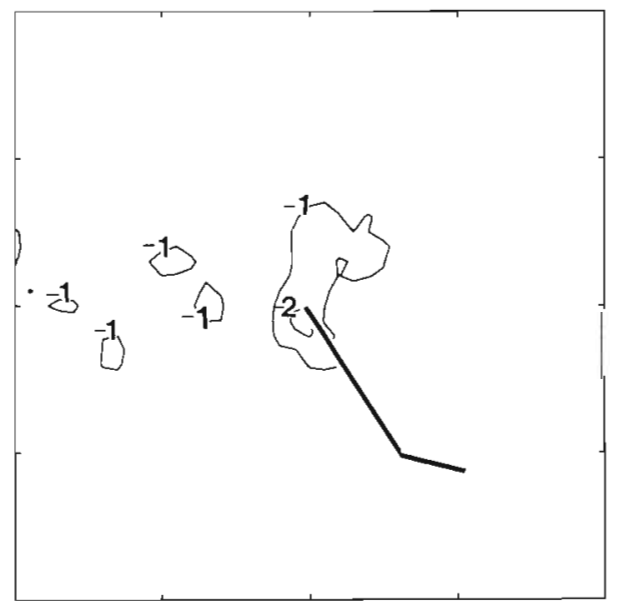

Pa2 flow field $v$

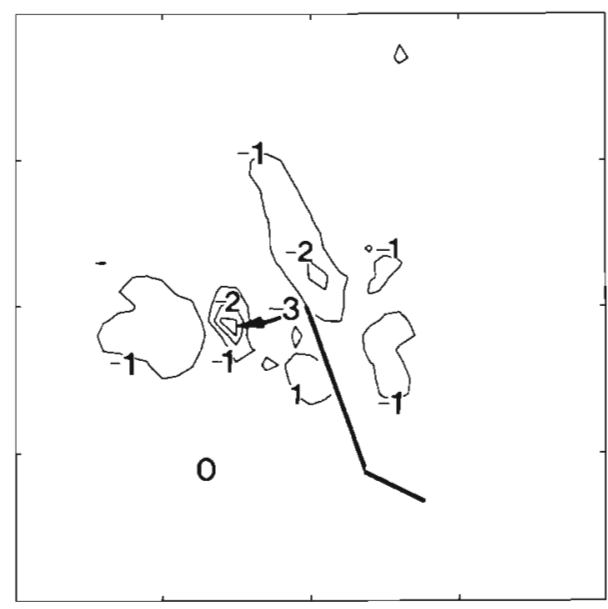

Pa3 flow field $v$

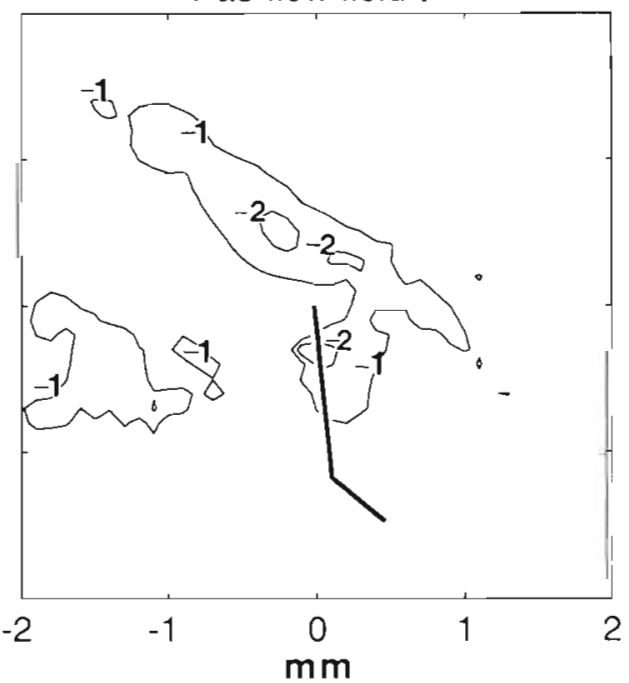

Fig. 5 (facing page and above). The feeding current of Paracalanus aculeatus females. (a) Flow field velocity. Contours represent fluid speeds and are plotted at $1 \mathrm{~mm} \mathrm{~s}^{-1}$ intervals. (b) Flow field geometry. Vectors indicate direction and magnitude of flow. Single large arrow represents copepod swimming trajectory. (c) Horizontal ( $u$ ) and vertical $(v)$ components of feeding current velocity. Isolines are plotted at $1 \mathrm{~mm} \mathrm{~s}^{-1}$ intervals 

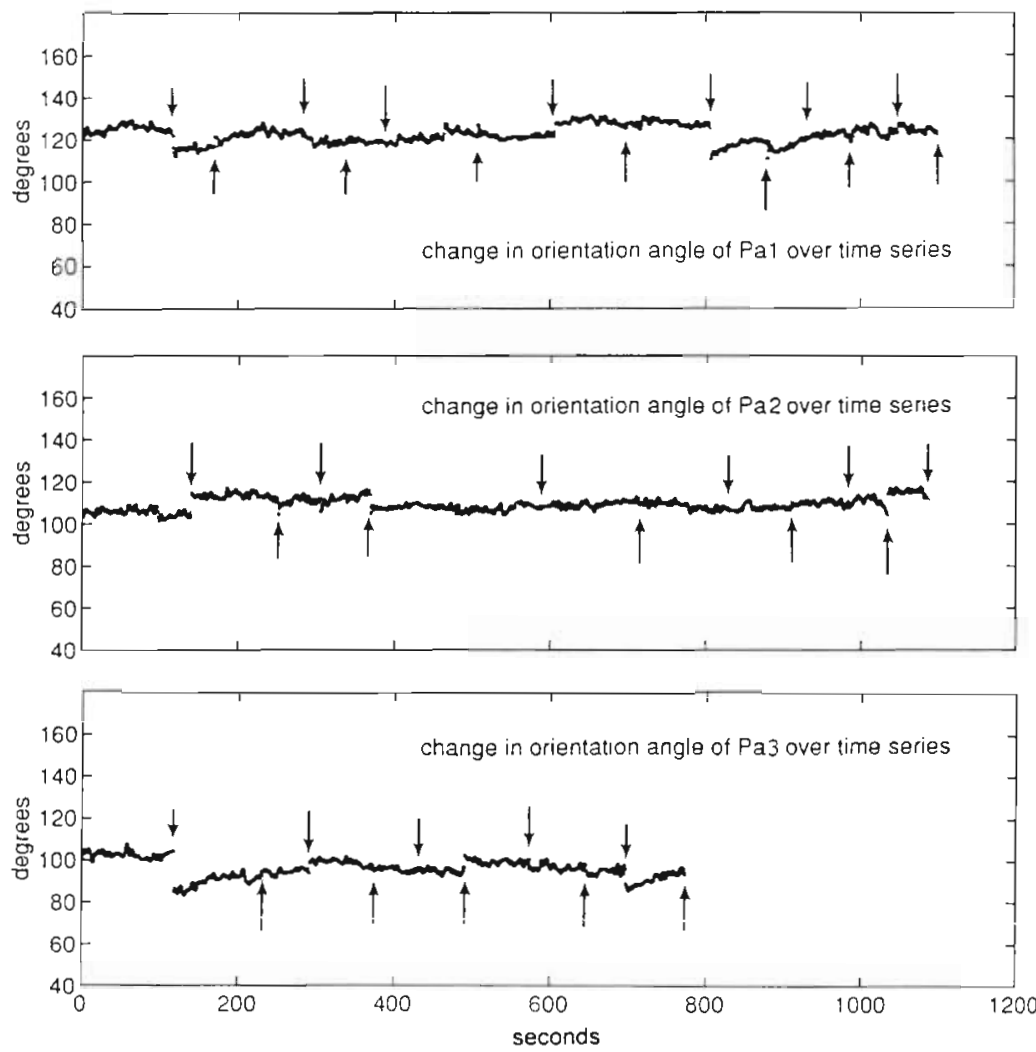

Fig. 6. Paracalanus aculeatus. Changes in body orientation (orientation angle) over each time-series. Arrows represent the end of each time-series. $y$-axis is angle of the copepod body axis (orientation angle) (see Fig. 1). Each dot is $0.033 \mathrm{~s}$ apart

The impact of body shape and velocity on flow fields around zooplankton has been investigated for ciliated larvae (Emlet 1990, Gallager 1993), cladocerans (Zaret \& Kerfoot 1980), and copepods (Tiselius \& Jonsson 1990). Changes in swimming velocity can alter flow field dimensions (Strickler 1982, Childress et al. 1987, Gallager 1993). The A1 of Centropages velificatus possess an array of closely spaced chemosensory and mechanosensory setae on the anterior-dorsal margin (Bundy \& Paffenhöfer 1993). Spacing between the setae on the proximal segments is 10 to $20 \mu \mathrm{m}$ and the setae are approximately $3 \mu \mathrm{m}$ in diameter and 30 to $80 \mu \mathrm{m}$ in length (Bundy unpubl. obs.). According to Cheer \& Koehl (1987), in a $5 \mathrm{~mm} \mathrm{~s}^{-1}$ flow, we should expect less than $40 \%$ of the flow impinging on the A1 to pass between these setae. Most of the flow must therefore be diverted around the setae and over the A. Evidence of this flow distortion is seen in the flow field patterns and elevated fluid velocities dorsal to $C$. velificatus (Fig. 3a, b). Neither flow separation around the copepod body nor deformation of flow lines in front of the A1 is seen in the flow field diagrams of the tethered $C$. velificatus. The absence of these flows around the tethered copepod and their presence around the freely swimming copepods indicates that contact rates of copepods with the surrounding fluid are controlled by 3 factors: the frequency and patterns of movement of the appendages which entrain fluid, the motion of the copepod relative to the fluid, and the distortion of fluid around the body of the copepod.

\section{Ecological considerations}

The role of turbulence

On the continental shelf of the southeastern United States, where Centropages velificatus and Paracalanus aculeatus co-occur (Bowman 1971), largescale hydrodynamic disturbances, in the form of wind-generated surface waves, tidal currents, and Gulf Stream frontal meanders, may disrupt stratification and add energy to the system. The present study shows that the spatial scales of the flow fields of both $C$. velificatus and $P$. aculeatus are smaller than the Kolmogorov length scale generated by all but the most energetic physical events, energy dissipation rate, $\varepsilon \approx 10^{-2}$ $\mathrm{cm}^{2} \mathrm{~s}^{-3}$, Kolmogorov length scale, $\eta \approx$ $1 \mathrm{~mm}$; Yamazaki et al. 1991). From our results, which are in concordance with the results of mathematical models of copepod feeding in turbulence (Kiørboe \& Saiz 1995), it can be predicted that when either of these species encounters high levels of turbulence in the field, the smallest turbulent eddies will not disrupt the feeding current. Because small-scale velocity fluctuations take the form of linear shear at these length scales, the streamlines of copepod feeding currents may occasionally be displaced by small-scale velocity fluctuations. Our data suggest that the flow fields of $P$. aculeatus would be more vulnerable to the effects of turbulent shear than the flow fields of $C$. velificatus, which are 3 times higher in velocity. Saiz \& Kiørboe (1995) found that clearance rates of Acartia tonsa feeding on diatoms were depressed at high levels of simulated turbulence and were minimally affected by lower levels. Also, the temporal scales of copepod feeding activity are $<1$ second to milliseconds, if one considers the time that a phytoplankton cell is entrained in the feeding current or the time for motile prey to execute escape maneuvers. Turbulent events are therefore infrequent or slow when considered in the context of 
the temporal scales of copepod feeding which involve detection, entrainment, and capture of food items.

\section{Feeding strategies}

The feeding current is the component of the flow field which is involved in detection, entrainment, and capture of food items by the predator. Copepod feeding currents serve different functions for different types of prey. The feeding strategies used to capture nonmotile prey which have limited escape capabilities differ from those used by a predator which must remain cryptic to avoid detection by prey which are capable of actively escaping. Foragers can maximize encounter rates by maximizing the volume within which prey are detected and captured, and by increasing swimming speed relative to their prey (Gerritsen \& Strickler 1977). Gallager (1993) found that a veliger larva can greatly increase the dimensions of its flow field, and consequently its perceptive volume, by hovering rather than sinking or swimming. Gerritsen \& Strickler (1977) predicted that predators feeding on slowly moving prey should adopt a cruising mode of foraging to maximize encounter rates. Behavioral plasticity allows a foraging organism to modify the efficiency with which it searches for different types and concentrations of prey (e.g. Cushing 1968, Rosenthal \& Hempel 1970, Gerritsen \& Strickler 1977, Bundy et al. 1993).

For herbivores, an extensive feeding current which entrains fluid from a large area around the copepod increases relative motion between predator and prey. It is not necessary for the copepod to increase its swimming speed if feeding current velocities are high and the food item is not capable of escaping the flow. In a patchy food environment, increasing speed relative to prey will increase the encounter rate for that prey, and at the same time, may move the forager out of a food patch. Therefore, slowly moving copepods like Paracalanus aculeatus, which feed primarily on nonmotile or slowly moving prey, can take advantage of a mechanism which increases relative velocity of food items, yet does not require that the copepod move great distances. If food items become scarce, this species can displace itself by ceasing appendage movements and sinking.

Interactions with motile prey are influenced by flow field geometry and velocity, both of which determine the extent of the hydrodynamic signal presented to prey. Shear and changes in fluid velocity have been implicated as the cues generated by the flow field which stimulate escape behaviors of potential prey (Singarajah 1975, Kirk \& Gilbert 1988, Williamson \& Vanderploeg 1988, Tiselius \& Jonsson 1990, Fields \&
Yen 1993). Because the force of the appendages against the resistance of the water propels a copepod through the water and is utilized to entrain prey-containing fluid, a foraging omnivorous copepod such as Centropages velificatus is faced with the dilemma of using a mechanism for propulsion and food capture which can also elicit escape responses from its potential prey. C. velificatus often moves in a sink/swim pattern, where the copepod swims slowly, then sinks with no appendage movement. The sinking phase of this pattern may allow the copepod to become cryptic to both predators and prey by eliminating the feeding current signal, and may also serve to keep the copepod within a limited search volume. As a possible benefit to the copepod predator, the feeding current disturbance may stimulate cryptic prey to move, thereby providing a mechanical signal which alerts the copepod to the presence of the prey.

Whether the flow field geometry is controlled by changing the coefficient of drag (by altering body orientation and swimming trajectory), or by altering the frequency and pattern of appendage movements, is not known. However, by changing the magnitudes of both fluid velocity and shear in the feeding current, Centropages velificatus may be capable of altering the strength of the hydrodynamic signal it presents to potential prey. Because plankton assemblages are composed of both zooplankton and phytoplankton, it may be beneficial for an omnivore to change its feeding behavior in response to changing abundance of animal and phytoplankton prey.

A disadvantage of an extensive feeding current is that it presents a large signal to potential predators Experiences in handling Paracalanus aculeatus and Centropages velificatus in the laboratory reveal that both species are capable of executing vigorous escape maneuvers in response to weak mechanical stimuli. These copepods have the ability to avoid predation by ceasing appendage movement, thereby becoming cryptic, and by executing pronounced escape movements.

\section{CONCLUSIONS}

The flow fields of the omnivore, Centropages velificatus, show differences between individuals in the location and magnitudes of velocity maxima. Swimming speeds are variable and body orientations relative to the swimming trajectory are different for each copepod. There is evidence in the flow field that fluid separates around the anterior of the copepod as it moves, creating a zone of reduced fluid velocity in front of the moving copepod. Because we lack information about flow velocity from lateral directions, 
quantitative analyses of shear and energy dissipation cannot be made in this study. We also cannot distinguish between divergence and convergence zones in the flow field. Due to the behavioral plasticity exhibited by this species, additional copepods should be observed before quantitative statements about the effects of body orientation and swimming trajectory on feeding current flow fields can be made. The information presented here, however, suggests that plasticity of behavior of this omnivorous calanoid allows the copepod to alter the magnitude of velocity and shear in the feeding current rapidly and therefore rapidly respond to encounters with different prey types and to changing levels of small-scale turbulence. In middle shelf waters, hydrodynamic regimes and the composition of prey populations can change rapidly. Therefore, a foraging copepod would benefit energetically from behavioral plasticity.

Centropages velificatus is found in high concentrations in the thermocline of the southeastern shelf (Paffenhöfer unpubl. obs.) where levels of turbulence are elevated. If shear from small-scale turbulence should become energetic enough to disrupt the feeding current, this omnivore may resort to carnivorous feeding and take advantage of the enhancement of contact rates afforded by increased turbulent mixing. Evidence from recent laboratory experiments shows that even low levels of simulated turbulence enhance clearance rates of the omnivore Acartia tonsa on ciliates (Saiz \& Kiørboe 1995)

The feeding current flow fields of the 3 Paracalanus aculeatus are similar in the location and magnitude of velocity and shear. The swimming speeds and the orientations of the copepods to the swimming trajectory are similar between individuals and there is little fluid separation or distortion around the copepod body. Because this species feeds mainly on phytoplankton and other prey with limited capacity to escape the feeding current, the ability to rapidly reduce the velocity and shear associated with the feeding current would not be advantageous, except possibly as a means of remaining cryptic to predators. In the outer shelf and oceanic waters where $P$ aculeatus is abundant and phytoplankton concentrations are low, a feeding mechanism which increased contact rates with food particles, yet did not require the organism to move long distances, would conserve energy and prevent the forager from moving out of resource patches.

The goal of this study was to characterize and compare the flow fields of an omnivorous and a predominantly herbivorous calanoid. The observed differences in flow fields are attributed to behavioral differences, i.e. changes in swimming velocity, body orientation and the frequency of mouthpart movements, and to differences in mouthpart morphology. This comparison of the activities of adult females of 2 species represents only a small part of the behavioral potential of copepods if epipelagic communities are considered: for example, we can expect considerable ontogenetic (Paffenhöfer pers, obs.) and major species-specific differences. We therefore consider this study, which was conducted at satiating food conditions, as an endeavor to provide initial insight into the motion behavior of freely swimming copepods. We expect that their activities in situ, under limiting food conditions in a heterogeneous environment, will vary from those observed here. Our comparative results, however, serve as an indicator of species-specific differences and intraspecific variability, and provide insight into their physical causes.

Acknowledgements. We thank Dr T. F. Gross for his help and advice and $\mathrm{Dr} J$. R. Nelson for reading and correcting the manuscript. Three anonymous reviewers provided valuable advice and comments. This research was supported by Skidaway Institute of Oceanography, and a National Science Foundation grant (grant OCE 90-00144) to G.A.P.

\section{LITERATURE CITED}

Alcaraz M, Paffenhöfer GA, Strickler JR (1980) Catching the algae: a first account of visual observations on filter feeding calanoids. In: Kerfoot WC (ed) The evolution and ecology of zooplankton communities. University Press of New England, Hanover, NH, p 241-248

Andrews JC (1983) Deformation of the active space in the low Reynolds number feeding current of calanoid copepods. Can J Fish Aquat Sci 40:1293-1302

Bainbridge R (1949) Movement of zooplankton in diatom gradients. Nature 163:910-911

Bowman TE (1971) The distribution of calanoid copepods off the southeastern United States between Cape Hatteras and Southern Florida. Smithsonian Contr Zool No. 96. Smithsonian Institution Press, Washington, DC

Bundy MH, Gross TF, Coughlin DJ, Strickler JR (1993) Quantifying copepod searching efficiency using swimming pattern and perceptive ability. Bull Mar Sci 53(1): $15-28$

Bundy MH, Paffenhöfer GA (1993) Innervation of copepod antennules investigated using laser scanning confocal microscopy. Mar Ecol. Prog Ser 1.02:1-14

Cannon HG (1928) On the feeding mechanism of the copepods Calanus finmarchicus and Diaptomus gracilis. $\mathrm{Br}$ J Exp Biol 6:131-144

Cheer AYL, Koehl MAR (1987) Paddles and rakes: flow through the bristled appendages of small organisms. J Theor Biol 129:17-39

Childress S, Koehl MAR, Miksis MS (1987) Scanning currents in Stokes flow and the efficient feeding of small organisms. J Fluid Mech 177:407-436

Cowles TJ, Strickler JR (1983) Characterization of feeding activity patterns in the planktonic copepod Centropages typicus Kroter under various food conditions. Limnol Oceanogr 28(1):106-115

Cushing DH (1968) Grazing by herbivorous copepods in the sea. $J$ Cons Perm Int Explor Mer 32(1):70-82 
Emlet RB (1990) Flow fields around ciliated larvae: effects of natural and artificial tethers. Mar Ecol Prog Ser 63:211-225

Emlet RB, Strathmann RR (1985) Gravity, drag, and feeding currents of small zooplankton. Science 228:1016-1017

Fields DM, Yen J (1993) Outer limits and inner structure: the 3-dimensional flow field of Pleuromamma xiphias (Calanoida: Metridinidae). Bull Mar Sci 53(1):84-95

Gallager SM (1993) Hydrodynamic disturbances produced by small zooplankton: a case study for the veliger larva of a bivalve mollusc. J Plankton Res 15(11):1277-1296

Gauld DT (1966) Swimming and feeding of planktonic copepods. In: Barnes $\mathrm{H}$ (ed) Some contemporary studies in marine science. George Allen and Unwin, Ltd, London, p 313-334

Gerritsen J, Strickler JR (1977) Encounter probabilities and community structure in zooplankton: a mathematical model. J Fish Res Bd Can 34:73-82

Gilbert JJ, Kirk KL (1988) Escape responses of the rotifer Keratella: description, stimulation, fluid dynamics and ecological significance. Limnol Oceanogr 33:1440-1450

Haury LR, Kenyon DE (1980) Experimental evaluation of the avoidance reaction of Calanus finmarchicus. J Plankton Res 2:35-44

Jonsson PR, Tiselius P (1990) Feeding behavior, prey detection and capture efficiency of the copepod Acartia tonsa feeding on planktonic ciliates. Mar Ecol Prog Ser 60:35-44

Kerfoot WC (1978) Combat between predatory copepods and their prey: Cyclops, Epischura, and Bosmina. Limnol Oceanogr 23(6):1089-1102

Kiørboe T, Saiz E (1995) Planktivorous feeding in calm and turbulent environments, with emphasis on copepods. Mar Ecol Prog Ser 122:135-145

Kirk KL, Gilbert JJ (1988) Escape behavior of Polyarthra in response to artificial flow stimuli. Bull Mar Sci 43(3): $551-560$

Koehl MAR, Strickler JR (1981) Copepod feeding currents food capture at low Reynolds number Limnol Oceanogr 26:1062-1073

Legier-Visser M, Mitchell JG, Okubo A, Fuhrman JA (1986) Mechanoreception in calanoid copepods: a mechanism for prey detection. Mar Biol 90:529-536

Paffenhofer GA, Bundy MH, Lewis KD, Metz C (1995) Rates of ingestion and their variability between individual calanoid copepods: direct observations. J Plankton Res 17: $1573-1585$

Paffenhöfer GA, Lewis KD (1990) Perceptive performance and feeding behavior of calanoid copepods. J Plankton Res 12(5):933-946

Paffenhöfer GA, Strickler JR, Alcaraz M (1982) Suspensionfeeding by herbivorous calanoid copepods: a cinematographic study. Mar Biol 67:193-199

Price HJ, Paffenhöfer GA (1986) Effects of concentration on the feeding of a marine copepod in algal monocultures and mixtures. J Plankton Res 8:119-128

Price HJ, Paffenhöfer GA, Strickler JR (1983) Modes of cell capture in calanoid copepods. Limnol Oceanogr 28 : $116-123$

This article was submitted to the editor
Rosenthal H, Hempel G (1970) Experimental studies in feeding and food requirements of herring larva (Clupea harengus L.). In: Steele JH (ed) Marine food chains. Oliver and Boyd, Edinburgh, p 344-364

Saiz E, Kiørboe T (1995) Predatory and suspension feeding of the copepod Acartia tonsa in turbulent environments. Mar Ecol Prog Ser 122:147-158

Singarajah KV (1975) Escape reactions of zooplankton: effects of light and turbulence. J Mar Biol Ass UK 55:627-639

Smith WHF, Wessel P (1990) Gridding with continuous curvature splines in tension. Geophysics 55(3):293-305

Storch O, Pfisterer O (1925) Der Fangapparat von Diaptomus. Zeit vergl Physiol 3:330-376

Strickler JR (1982) Calanoid copepods, feeding currents, and the role of gravity. Science 218:158-160

Strickler JR (1984) Sticky water: a selective force in copepod evolution. [n: Meyers DG, Strickler JR (eds) Trophic interactions within aquatic ecosystems. AAAS Symposium 85 Westview Press, Boulder, CO

Strickler JR (1985) Feeding currents in calanoid copepods: two new hypotheses. In: Laverack MS (ed) Physiological adaptations of marine animals. J Symp Soc Exp Biol 89 $459-485$

Svetlichnyy LS (1987) Speed, force and energy expenditure in the movement of copepods. Oceanology 27(4): $497-502$

Tiselius P, Jonsson PR (1990) Foraging behaviour of six calanoid copepods: observations and hydrodynamic analysis. Mar Ecol Prog Ser 66:23-33

Vanderploeg HA, Paffenhöfer GA (1985) Modes of algal capture by the freshwater copepod Diaptomus sicilis and their relation to food-size selection. Limnol Oceanogr 30 $871-885$

Weiss DG, Keller F, Gulden J, Maile W (1986) Towards a new classification of intracellular particle movements based on quantitative analyses. Cell Motil Cytoskel 6:128-135

Williamson CE (1987) Predator-prey interactions between omnivorous diaptomid copepods and rotifers: the role of prey morphology and behavior. Limnol Oceanogr 32(1): $167-177$

Williamson CE, Vanderploeg HA (1988) Predatory suspension-feeding in Diaptomus: prey defenses and the avoidance of cannibalism. Bull Mar Sci 43:561-572

Yamazaki H, Osborn TR, Squires KD (1991) Direct numerical simulation of planktonic contact in turbulent flow. J Plankton Res 13(3):629-643

Yen J, Fields DM (1992) Escape responses of Acartia hudsonica (Copepoda) nauplii from the flow field of Temora longicornis (Copepoda). Arch Hydrobiol Beih Ergebn Limnol 36:123-134

Yen J, Sanderson B, Strickler JR, Okubo A (1991) Feeding currents and energy dissipation by Euchaeta rimana, a subtropical pelagic copepod. Limnol Oceanog 36(2): $362-369$

Zaret RE, Kerfoot WC (1980) The shape and swimming technique of Bosmina longirostris. Limnol Oceanogr 25(1): $126-133$

Manuscript first received: October 25, 1994 Revised version accepted: October 20, 1995 